๑С. Р. Галич, Д. М. Щурко, М. І. Щурко, О. М. Каланжова

Одесъкий національний медичний університет

\title{
ПРОГНОСТИЧНІ КРИТЕРІї ЗАГРОЗИ АНТЕНАТАЛЬНОЇ ЗАГИБЕЛІ ПЛОДА ПРИ ВРОДЖЕНИХ ВАДАХ РОЗВИТКУ
}

Мета дослідження - прослідкувати динаміку внутрішньоутробного тенатогенезуплодів із вродженими вадами розвитку. Динаміку внутрішньоутробного тенатогенезу було прослідковано у 24-х внутрішньоутробних плодів, які мали вроджені вади розвитку.

Матеріали та методи. Цим пацієнткам щоденно здійснювали доплерометрію кровоплину в маткових артеріях, пупковій артерії і середньомозковій артерії та низькочастотну п'єзоелектричну тромбоеластографрію із моменту реєстрації загрозливої ознаки та до моменту констатації внутрішньоутробної загибелі плода. Визначали коефіцієнти кореляції за методом Спірмена між кількісними показниками та вірогідністю антенатальної загибелі плода.

Результати дослідження та їх обговорення. Аналіз отриманих даних показав, що при порушеннях кровоплину виключно у матковій артерії ризик антенатальної загибелі плода відсутній. При порушеннях кровоплину у пупковій артерії та поєднанні цих порушень із гіперкоагуляцією висока вірогідність настання антенатальної загибелі плода впродовж від 2-3-х до 7-14-ти діб. Найвищий ризик антенатальної загибелі плода впродовж 2-4-х год обумовлений порушенням кровоплину у середньомозковій артерії на тлі гіперкоагуляції та пригнічення фрібринолізу.

На основі оцінки показників кровоплину в судинах фетоплацентарного комплексу та гемостазу методом низькочастотної п'єзоелектричної тромбоеластографії у вагітних із вродженими вадами розвитку плода, поєднаних із плацентарною диссункцією, було розроблено метод прогнозування ризику антенатальної загибелі плода, який полягає в оцінці стану гемодинаміки внутрішньоутробного плода (доплерометрія) із одночасним дослідженням за допомогою низькочастотної п'єзоелектричної тромбоеластографрії. При констатації порушень кровоплину в артеріях пуповини чи (та) середньомозковій артерії, поєднаних із гіперкоагуляцією та пригніченням фрібринолізу, рекомендовано термінове розродження впродовж доби.

Висновок. Запропонований алгоритм ведення вагітності, обстеження та розродження приводить до відсутності антенатальної загибелі плода, зниження показника перинатальної смертності, перинатальної захворюваності.

Ключові слова: вроджені вади розвитку; антенатальна загибель плода; доплерометрія; система гемостазу.

ПРОГНОСТИЧЕСКИЕ КРИТЕРИИ УГРОЗЫ АНТЕНАТАЛЬНОЙ ГИБЕЛИ ПЛОДА ПРИ ВРОЖДЕННЫХ ПОРОКАХ РАЗВИТИЯ

Цель исследования - проследить динамику внутриутробного тенатогенеза плодов с врожденными пороками развития. Динамику внутриутробного тенатогенеза было прослежено в 24-х внутриутробных плодов, которые имели врожденные пороки развития.

Материалы и методы. Этим пациенткам ежедневно осуществляли допплерометрию кровотока в маточных артериях, пупочной артерии и среднемозговой артерии и низкочастотную пьезоэлектрическую тромбоэластографию с момента регистрации угрожающего признака и до момента констатации внутриутробной гибели плода. Определяли коэфрфициенты корреляции по методу Спирмена между количественными показателями и вероятностью антенатальной гибели плода.

Результаты исследования и их обсуждение. Анализ полученных данных показал, что при нарушениях кровотока исключительно в маточной артерии риск антенатальной гибели плода отсутствует. При нарушениях кровотока в пупочной артерии и сочетании этих нарушений с гиперкоагуляцией высокая вероятность наступления антенатальной гибели плода в течение от 2-3-х до 7-14-ти суток. Самый высокий риск антенатальной гибели плода в течение 2-4-х часов обусловлен нарушением кровотока в среднемозговой артерии на фроне гиперкоагуляции и угнетения срибринолиза.

На основе оценки показателей кровотока в сосудах фетоплацентарного комплекса и гемостаза методом низкочастотной пьезоэлектрической тромбоэластографии у беременных с врожденными пороками развития плода, сопряженных с плацентарной диссункцией, был разработан метод прогнозирования риска антенатальной гибели плода, который заключается в оценке состояния гемодинамики внутриутробного плода (допплерометрия) с одновременным исследованием с помощью низкочастотной пьезоэлектрической тромбоэластографии. При констатации нарушений кровотока в артериях пуповины или (и) среднемозговой артерии, сочетанных с гиперкоагуляцией и угнетением фибринолиза, рекомендуется срочное родоразрешение в течение суток.

Вывод. Предложенный алгоритм ведения беременности, обследования и родоразрешения приводит к отсутствию антенатальной гибели плода, снижению показателю перинатальной смертности, перинатальной заболеваемости.

Ключевые слова: врожденные пороки развития; антенатальная гибель плода; допплерометрия; система гемостаза.

PROGNOSTIC CRITERIA OF THE THREAT OF ANTENATAL FETUS DEATH IN THE CONGENITAL DEVELOPMENT PERILS

The aim of the study - to monitor the dynamic tenatogenesis of intrauterine fetuses with birth defects. The dynamics of fetal tenatogenesis was observed in 24 fetus that had congenital defects.

Materials and Methods. These patients undergo daily Doppler velocimetry in the uterine arteries, umbilical artery and mesencephalic arteries and low-frequency piezoelectric thromboelastography from the date of registration and threatening signs until the statement of intrauterine fetal death. We determined the correlation coefficients between the method of Spearman and quantitative indicators likely antenatal fetal death.

Results and Discussion. Analysis of the data showed that only flow disturbances in uterine the artery risk of antenatal fetal death is absent. In violation of blood flow in the umbilical artery and the combination of these disorders of hypercoagulation high 
probability of antenatal fetal death over from 2-3 to 7-14 days. The highest risk antenatal of fetal death within 2-4 hours due to violation of blood flow in the medium cerebral artery against the background of a hypercoagulable state and inhibition of fibrinolysis.

Based on the performance evaluation of blood flow in vessels feto-placental complex and hemostasis by low-frequency piezoelectric thromboelastography in pregnant women with congenital malformations of the fetus, combined with placental dysfunction, we developed a method of forecasting risk antenatal fetal death, which is the assessment of hemodynamics fetus (Doppler) with simultaneous study of low frequency piezoelectric thromboelastography. In finding violations of blood flow in the umbilical artery, or (and) medium cerebral artery combined with hypercoagulation and inhibition of fibrinolysis, recommended urgent accouchement throughout the day.

Conclusions. The proposed algorithm of pregnancy, delivery and examination leads to a lack of antenatal fetal death, perinatal decrease of mortality, perinatal morbidity.

Key words: congenital malformations; antenatal fetal death; Doppler velocimetry;

Вступ. Проблема антенатальної загибелі плода (АЗП) продовжує залишатись актуальною, соціально значимою та недостатньо вивченою. Антенатальні втрати $\epsilon$ всесвітньою проблемою [1]. У зв'язку із розвитком перинатальної медицини та удосконаленням перинатальної служби частота перинатальних втрат дещо знизилася у другій половині XX століття [2]. За останні роки в усьому світі значно зменшився показник перинатальної смертності, однак АЗП залишається високою і становить більше від 50 \% в структурі перинатальних втрат [3].

В умовах зміни демографрічної ситуації в Україні, а також зниження народжуваності, збереження кожної вагітності та народження здорової дитини є одним із основних завдань медичної служби. На цьому тлі АЗП продовжує вносити суттєвий вклад у структуру перинатальної смертності в Україні, де сягає 77,9 \% та не має тенденції до зниження [4]. Така частота цієї патології дає привід до вивчення їі чинників, патогенетичних механізмів, пошуку прогностичних та профрілактичних заходів. А це можливо лише із урахуванням як особливостей преморбідного фону, так і менеджменту прегравідарного періоду [5].

META ДОСЛІДЖЕННЯ - прослідкувати динаміку внутрішньоутробного танатогенезу плодів із вродженими вадами розвитку.

МАТЕРІАЛИ ТА МЕТОДИ. Динаміку внутрішньоутробного танатогенезу було прослідковано у 24-х внутрішньоутробних плодів, які мали вроджені вади розвитку. Цим пацієнткам щоденно здійснювали доплерометрію кровоплину в маткових артеріях (МА), пупковій артерії (ПА), середньомозковій артерії (СМА) і аорті плода (АП) та низькочастотну п'єзоелектричну тромбоеластограсрію (НПТЕГ) із моменту реєстрації загрозливої ознаки та до моменту констатації внутрішньоутробної загибелі плода. Усі матері дітей відмовились від термінового розродження внаслідок наявності летальних ВBР, про що були отримані відповідні інорормовані відмови. Додатково було вирахувано час, який пройшов із моменту реєстрації того чи іншого порушення (кровоплину чи гемокоагуляції) до констатації антенатальної загибелі плода.

Визначали коесріцієнти кореляції за методом Спірмена між кількісними показниками та вірогідністю АЗП. Отримані дані дозволили визначити етапність та тривалість порушень кровоплину, виразність порушень коагуляції, які асоційовані із критичним станом плода та надзвичайно високим ризиком його загибелі, притаманним ВВР плода.

РЕЗУЛЬТАТИ ДОСЛІДЖЕННЯ ТА ЇХ ОБГОВОРЕННЯ. Аналіз отриманих даних показав (табл. 1), що при порушеннях кровоплину виключно у МА ризик АЗП відсутній $(r=0,00)$. При порушеннях кровоплину у ПА та поєднанні цих порушень із гіперкоагуляцією висока вірогідність настання АЗП упродовж від 2-3-х до 7-14-ти діб (r=0,52 та $r=0,56$ відповідно).

Ризик антенатальної загибелі плода впродовж 24-х год зростає за умови порушень кровоплину у ПА та АП $(r=0,82)$, а також при порушеннях кровоплину в ПА та СМА $(r=0,69)$. Поєднання порушень кровоплину в ПА з гіперкоагуляцією та пригніченням фрібринолізу збільшує вірогідність настання АЗП упродовж 2-3-х діб $(r=0,78)$.

Найвищий ризик АЗП упродовж 2-4-х год обумовлений порушенням кровоплину в СМА на тлі гіперкоагуляції та пригніченням фрібринолізу.

На основі оцінки показників кровоплину в судинах ФПК та гемостазу методом НПТЕГ у вагітних із ВВР плода, поєднаних із плацентарною дисфункцією (ПД), було розроблено метод прогнозування ризику АЗП, який полягає в оцінці стану гемодинаміки внутрішньоутробно-

Таблиця 1. Тривалість та етапність порушень кровоплину та коагуляції при загрозі антенатальної загибелі плода у вагітних із ВВР та пд

\begin{tabular}{|l|c|c|c||}
\hline \multicolumn{1}{|c|}{ Показник } & $\begin{array}{c}\text { Коефіцієнт кореляції } \\
\text { (р>0,99 \%) }\end{array}$ & Тривалість & $\begin{array}{c}\text { Ризик антенатальної } \\
\text { загибелі плода }\end{array}$ \\
\hline Порушення кровоплину в МА ізольовані & $\mathrm{r}=+0,00$ & Більше від 14 діб & Відсутній \\
\hline Порушення кровоплину в ПА ізольовані & $\mathrm{r}=+0,52$ & $7-14$ діб & Вірогідний \\
\hline Порушення кровоплину в ПА та АП & $\mathrm{r}=+0,82$ & 24 год & Високий \\
\hline Порушення кровоплину в ПА та СМА & $\mathrm{r}=+0,69$ & 24 год & Високий \\
\hline Порушення кровоплину в ПА та гіперкоагуляція & $\mathrm{r}=+0,56$ & $2-3$ доби & Вірогідний \\
\hline $\begin{array}{l}\text { Порушення кровоплину в ПА, гіперкоагуляція та } \\
\text { пригнічення ффібринолізу }\end{array}$ & $\mathrm{r}=+0,78$ & $2-3$ доби & Високий \\
\hline $\begin{array}{l}\text { Порушення кровопливу в СМА, гіперкоагуляція, } \\
\text { пригнічення фібринолізу }\end{array}$ & $\mathrm{r}=+0,98$ & $2-4$ год & Максимальний \\
\hline \hline
\end{tabular}


го плода (доплерометрія) із одночасним дослідженням НПТЕГ. При констатації порушень кровоплину в АП чи (та) СМА, поєднаному із гіперкоагуляцією та пригніченням фрібринолізу, рекомендовано термінове розродження впродовж доби.

При порушенні кровоплину в ПА та гіперкоагуляції показано розродження впродовж 2-3-х діб, що дає можливість здійснити профрілактику синдрому дихальних розладів кортикостероїдами в терміні вагітності до 34-х тижнів.
За умови нормальних показників НПТЕГ та порушень кровоплину в ПА безпечно підготувати внутрішньоутробну дитину до народження впродовж 7-ми діб.

Таким чином, у випадках поєднання ВВР плода із ПД та виникнення порушень кровоплину визначення часу розродження має здійснюватися на підставі виключно порушень у СМА та може бути прогностичним чинником АЗП.

Проведено аналіз ефективності запропонованого алгоритму ведення вагітності, обстеження та розродження вагітних із ВВР плода (рис. 1).

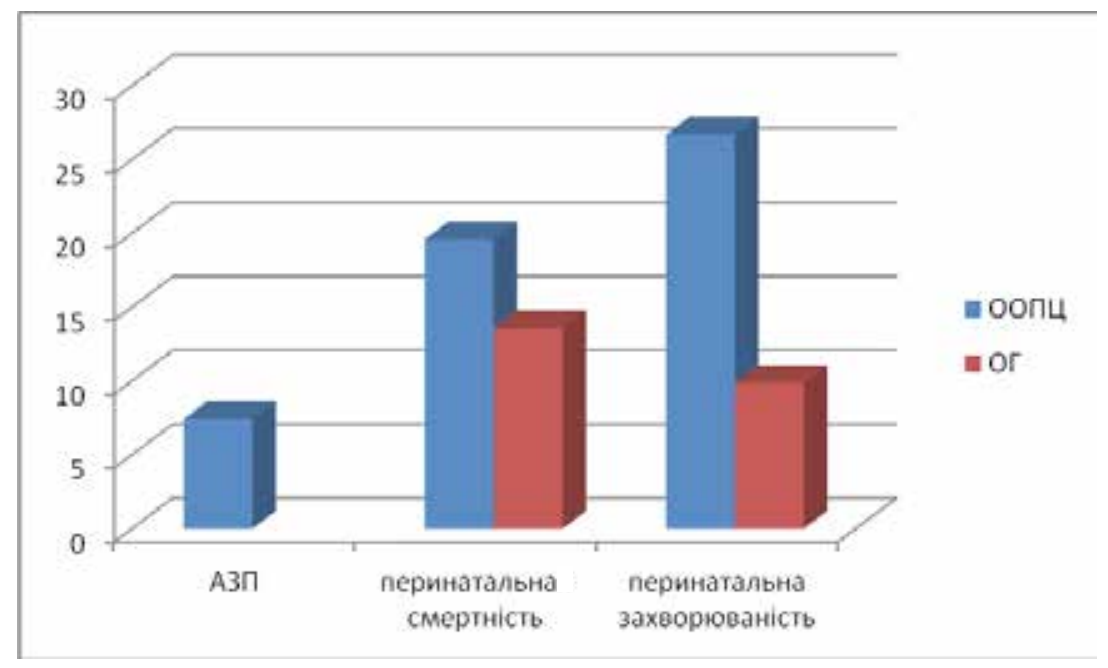

Рис. 1. Ефективність алгоритму ведення вагітності, обстеження та розродження при ВВР плода.

ВИсновкИ. Запропонований алгоритм ведення вагітності, обстеження та розродження приводить до відсутності антенатальної загибелі плода, зниження показника перинатальної смертності у 1,4 раза, перинатальної захворюваності по окремих групах захворюваності (по- логова травма, внутрішньоутробна гіпоксія та асфріксія, дихальні розлади) -у 2,7 раза.

ПЕРСПЕКТИВИ ПОДАЛЬШИХ ДОСЛІДЖЕНЬ. ДаНИЙ метод може використовуватися для зменшення перинатальної захворюваності та смертності.

\section{СПИСОК ЛІТЕРАТУРИ}

1. Туманова В. А. Проблемы антенатальных потерь / В. А. Туманова, И. В. Баринова // Российский вестник акушера-гинеколога. - 2009. - № 5. - С. 39-45.

2. Goldenberg R. L. Commentary: reduciny the world's stillbirths / R. L. Goldbery, E. M. MacClure, J. M. Belizan // BMC Pregnancy Stillbirth. - 2009. - № 7. - Suppl. 1. - P. 1.

3. Silver P. H. Fetal death / P. H. Silver // Obstet. Gynecol. - 2007. - Vol. 109, № 1. - P. 153-167.

\section{REFERENCES}

1. Tumanova, V.A., \& Barinova, I.V. (2009). Problemy antenatalnykh poter [Problems of antenatal losses]. Rossiyskiy vestnik akushera-ginekologa - Russian Journal of the ObstetricianGynecologist, 5, 39-45 [in Russian].

2. Goldenberg, R.L., Goldbery, R.L., MacClure, E.M., \& Belizan, J.M. (2009). Commentary: reduciny the world's stillbirths. BMC Pregnancy Stillbirth, 7, (1), 1.

3. Silver, P.H. (2007). Fetal death. Obstet. Gynecol., 1, (109), 153-167.

4. Khomenko, V.A., Bezuglaya, I.A., \& Mogylevkina, I.A.
4. Хоменко В. А. Антенатальная гибель плода: чем отличаются такие беременности? / В. А. Хоменко, О. А. Безуглая, И. А. Могилевкина // Таврический медико-биологический вестник. - 2012. - Т. 15, № 2, ч. 2. - С. 201-203.

5. Нікогосян Л. Р. Аналіз частоти антенатальної загибелі плоду у вагітних в Одеському регіоні за 2011-2015 роки / л. Р. Нікогосян // Запорожский медицинский журнал. - 2012. - № 6 (75). - С. 8-9.
(2012). Antenatalnaya gibel ploda: chem otlichayutsa takie beremennosti? [Antenatal fetal death: how do these pregnancies differ?]. Tavricheskiy mediko-biologicheskiy vestnik - Tavrichesky Medico-Biological Journal, 2, (5), 201-203 [in Russian].

5. Nikogosyan, L.R. (2012). Analiz chastoty antenatalnoi zahybeli plodu u vahitnykh v Odeskomu rehioni za 2011-2015 roky [Analysis of frequency of antenatal fetus death in pregnant women in Odesa region for 2011-2015]. Zaporozhskiy meditsinskiy zhurnal - Zaporozhye Medical Journal, 6, (75), 8-9 [in Ukrainian].

Отримано 06.02.17 